\title{
The influence of chemical reaction conditions upon poly(styrene- methyl methacrylate-acrylic acid) synthesis: Variations in nanoparticle size, colour and deposition methods
}

\author{
Rui D. V. Fernandes (D) | Pedro Gomes ID | Andrea Zille ID | António P. Souto
}

2C2T - Centro de Ciência e Tecnologia Têxtil, Universidade do Minho, Campus de Azurém, Guimarães, Portugal

\section{Correspondence}

Rui D. V. Fernandes, 2C2T - Centro de Ciência e Tecnologia Têxtil, Universidade do Minho, Campus de Azurém, 4800-058 Guimarães, Portugal.

Email: ruidvfernandes@gmail.com

\section{Funding information}

Fundação para a Ciência e a Tecnologia, Grant/Award Number: IF/00071/2015, PTDC/CTM-TEX/28295/2017, SFRH/BD/145269/2019 and UID/ CTM/00264/2019; European Regional Development funds (FEDER);

Competitiveness and Internationalization Operational Program (POCI) - COMPETE, Grant/Award Number: POCI-01-0145FEDER-007136

\begin{abstract}
Monodisperse latex nanospheres of poly(styrene-methyl methacrylate-acrylic acid) with different sizes were synthetised by soap-free emulsion copolymerisation and applied onto polyamide 6,6 fabrics by two methods, ie, gravitational sedimentation and dip-drawing. Different-sized nanospheres were synthetised by varying temperature and stirring velocity as reaction parameters. Scanning electron microscopy and scanning transmission electron microscopy were used to evaluate nanosphere sizes and deposition structures. The results showed two different nanosphere structural arrangements on the fabric surface, a hexagonal packed centre structure in the even surfaces and a square arrangement in the out-of-plane surfaces. Different colours were observed according to particle size, namely, violet ( $c a .170 \mathrm{~nm})$, blue $(c a .190 \mathrm{~nm})$, green $(c a .210 \mathrm{~nm})$, yellow $(c a .230 \mathrm{~nm})$ and red $(c a .250 \mathrm{~nm})$. An iridescence effect was also observed, displaying different colours at different observation angles. By controlling the size of the nanospheres it was possible to obtain different, brilliant and iridescent colours. Using different nanosphere sizes it was possible to obtain different interplanar distances and to control the light scattering in the crystalline lattice planes, obtaining Bragg diffraction patterns.
\end{abstract}

\section{1 | INTRODUCTION}

In the textiles industry, the dyeing and finishing processes cause substantial pollution because of the large amounts of chemicals used and the heavy water consumption. ${ }^{1}$ However, there is a more ecological way of adding colour to fabrics, which is called structural coloration. ${ }^{2}$ Structural colour is produced through interactions between light and highly ordered nanostructures and it can be found in nature in animals, plants and fruits for the purpose of camouflage, communication or mating. ${ }^{3-5}$ By using dielectric colloidal photonic crystals (PCs) (silica or polymer), it is possible to obtain brilliant structural colours with iridescence and no photo-fading. ${ }^{6}$ PCs allow the formation of structures with periodic variation in their dielectric properties called photonic band gap ( $\mathrm{PBG}$ ), which is capable of confining and controlling the propagation of light. ${ }^{7}$ If the
PBG falls into the visible light range between 380 and $780 \mathrm{~nm}$, the visible light of specific wavelengths is not allowed to propagate in the PC structure, thus being selectively reflected by Bragg's diffraction law. Moreover, structural colour can vary, changing the particle size or the angle of incidence of light. ${ }^{8}$ Bragg diffraction is obtained when the wavelength of incident light similar to the atomic spacing is scattered in the crystalline lattice planes, with a defined interplanar distance producing constructive interference. ${ }^{9}$ Spherical colloidal PCs can self-assemble into different structures. They can be one-dimensional, two-dimensional (2D) or three-dimensional (3D). ${ }^{10-12} 2 \mathrm{D}$ nanospheres present hexagonal closely packed layers and in 3D they present mainly face-centred cubic (FCC) arrays. 3D PCs have been researched in multiple fields, leading to several applications in sensors, ${ }^{10,13,14}$ ink-jet printing ${ }^{15}$ lithography ${ }^{16}$ and electronic devices. ${ }^{17,18}$ 
There have been some developments in the textiles field regarding structural coloration, mainly using synthetic polyester fibres as substrate, due to their unique properties such as smoothness, low moisture and flat surfaces. ${ }^{19-22}$ However, natural fibres like cotton have also been the subject of investigation. ${ }^{8,23,24}$ Recently, Liu et $\mathrm{al}^{19-21}$ reported the deposition of poly(styrene-methacrylic acid) (P(St-MAA)) PCs via gravitational sedimentation and vertical deposition in polyester fabrics, with structural coloration and iridescence. They studied the optical properties, self-assembly behaviour and formation mechanism of PCs, discovering that using a black substrate enhances the chroma of the structural colour. Gao et $\mathrm{al}^{24}$ reported the deposition of silica-based PCs via gravitational sedimentation in woven cotton fabrics, obtaining structural colours without iridescence using adequate surface properties and yarn spacing. The ability to obtain colours that remain stable at different observation angles is the first requirement in producing real colours.

Very few studies have been carried out on this subject using different-sized pure poly(styrene-methyl methacrylate-acrylic acid) (P(St-MMA-AA)) PCs and textiles as a substrate for deposition. Zeng et $\mathrm{al}^{23}$ fabricated a superhydrophobic fabric using three different-sized P(StMMA-AA) PCs on cotton coated with a polyacrylate adhesive.

Yuan et $\mathrm{al}^{25}$ used a totally different approach, producing electrospun poly(vinyl alcohol)-coated P(St-MMA-AA) nanofibres and obtaining non-woven assemblies with tunable structural colours. Shi et $\mathrm{al}^{26}$ produced a highly adhesive polydopamine coating to fix one size of $\mathrm{P}(\mathrm{St}-$ MMA-AA) PCs onto a cotton fabric. In previous research we also made progress with cotton by adopting different deposition methods using single-sized nanospheres. ${ }^{27,28}$ In the current study, monodisperse latex nanospheres of P(StMMA-AA) with different particle sizes were synthetised and deposited onto synthetic hydrophobic polyamide (PA) fabrics in order to understand and optimise the relationships between the colour formation, the adhesion ability and the dimensions of the PCs.

\section{$2 \mid$ EXPERIMENTAL}

\section{1 | Materials}

Styrene (St), methyl methacrylate (MMA), acrylic acid (AA) and other analytical grade reagents were purchased from Sigma-Aldrich, and used without further purification. Commercial black PA 6,6 plain fabric $\left(61.50 \mathrm{~g} / \mathrm{m}^{2}\right)$, 67 warp and 47 weft yarns, 5.60 and 3.00 Tex, respectively, was used as substrate to deposit the P(St-MMA-AA) nanoparticles.

\section{2 | Preparation of monodisperse $\mathbf{P}($ St- MMA-AA) composite nanospheres}

Monodisperse composite latex nanospheres of P(StMMA-AA) were synthetised by soap-free emulsion copolymerisation as previously described. ${ }^{29}$ Briefly, St (20.00 g), MMA (1.00 g), AA (1.00 g), distilled water $\left(\mathrm{dH}_{2} \mathrm{O}, 100.00 \mathrm{~g}\right)$, sodium dodecyl sulphate (0-0.004 g) and ammonium bicarbonate $(0.50 \mathrm{~g})$ were added sequentially to a three-necked flask equipped with a nitrogen gas inlet, a reflux condenser and a mechanical stirrer. The reaction of the mixture was initiated at $70^{\circ} \mathrm{C}$ for 30 minutes. Following the addition of an aqueous solution of sodium persulphate $\left(0.48 \mathrm{~g}\right.$ of $\mathrm{Na}_{2} \mathrm{~S}_{2} \mathrm{O}_{8}$ dissolved in $15000 \mathrm{~g}$ of $\mathrm{dH}_{2} \mathrm{O}$ ), polymerisation was carried out at $60,70,80$ and $90^{\circ} \mathrm{C}$ for 5 hours at $300 \mathrm{rpm}$ in order to obtain a homogeneous latex with monodispersed particles. Variations in the stirring speed were also performed, at 20.9, 31.4 and $41.9 \mathrm{rad} / \mathrm{s}$, with a constant temperature of $80^{\circ} \mathrm{C}$. The resulting $\mathrm{P}(\mathrm{St}-\mathrm{MMA}-\mathrm{AA})$ composite latex nanospheres were used without further purification.

\subsection{Fourier Transform-infrared spectroscopy with attenuated total reflection}

A Nicolet Avatar 360 Fourier Transform-infrared (FTIR) spectrometer (Madison), with a horizontal attenuated total reflection (ATR) accessory composed of a zinc selenide crystal, was used to record the ATR-FTIR spectra of the nanospheres. Forty-five scans at a spectral resolution of $4 \mathrm{~cm}^{-1}$ over a range of $400-4000 \mathrm{~cm}^{-1}$ were conducted. All measurements were recorded in triplicate.

\subsection{Dynamic light scattering and zeta potential measurements}

The size distribution, polydispersity index (PDI) and zeta potential of the nanospheres were measured by dynamic light scattering (DLS) and electrophoretic light scattering (ELS) using a Zeta Sizer-Nano (Malvern Instruments). Data were collected after 30 scans at a constant temperature of $25 \pm 1^{\circ} \mathrm{C}$. Zeta potentials were measured in solution at a moderate electrolytic concentration. Each value was obtained by averaging the measurements of three samples.

\section{5 | Deposition of PCs by the dip- drawing method}

A piece of PA 6,6 plain fabric $(3 \times 3 \mathrm{~cm})$ was dipped in the reaction mixture $(15 \% \mathrm{wt})$ and dried at $40^{\circ} \mathrm{C}$ in a Petri dish. Tests with a dilution of 1:20 were also performed; 
the fabric was dipped five times (until a good structural colour and iridescence were observed) then dried at $40^{\circ} \mathrm{C}$ in a Petri dish.

\subsection{Scanning electron microscopy and scanning transmission electron microscopy}

Morphological analyses of the PCs and PC-coated fabrics were carried out by scanning electron microscopy (SEM) and scanning transmission electron microscopy (STEM) with an ultra-high resolution field emission gun (FEI NOVA 200 Nano SEM). PC-coated fabric samples were covered with a thin film of gold/palladium $(80: 20)$ in a $208 \mathrm{HR}$ high-resolution sputter coater (Cressington) coupled to a MTM-20 high-resolution thickness controller (Cressington).

\subsection{Optical microscopy}

Microscopic optical images were obtained by a Leica DM750 M microscope with a built-in Leica MC 170 HD camera. Images were taken at $10 \times$ and $20 \times$ magnification with $\mathrm{Hi}$ Plan Epi lenses.

\subsection{Diffuse reflectance spectroscopy}

The PC-coated PA fabric coloration was evaluated using a Shimadzu ultraviolet 2600 spectrophotometer at standard illuminant D65 (Large Area View /spec. including d/8, D65/10). Spectral reflectance values for each sample were obtained at $10 \mathrm{~nm}$ intervals within the visible spectrum, which ranged from 360 to $700 \mathrm{~nm} . L^{*}, a^{*}$ and $b^{*}$ are the coordinates of the colour in the colour space, based on the theory that colour is perceived by black-white ( $L^{*}$, lightness), red-green $\left(a^{*}\right)$ and yellow-blue $\left(b^{*}\right)$ sensations.

\section{9 | Glossmeter analysis}

The specular gloss observed from a sample is the relative luminous reflectance factor in the mirror direction. The specular gloss of the commercial black PA fabric, both uncoated and coated with PCs, was measured with a GB-4520 microtri-gloss meter (BYK-Gardner) at incident angles of $20^{\circ}, 60^{\circ}$ and $85^{\circ}$ at measuring fields of $9 \times 9,9 \times 18$ and $7 \times 42 \mathrm{~mm}$, respectively. The multi-angle glossmeter was calibrated with a black gloss standard (GB-4522; 20 : 92, 60': 95 and $85^{\circ}$ : $99)$ built into the holder. For each angle and sample, the specular gloss was recorded.

\subsection{0 | Photographs}

Digital photographs of the fabrics coated with PCs were taken with a Canon EOS 750D digital camera. The images were acquired in a light chamber under a D65 light source. In the case of the multi-angle photographs, the sample was set at different angles while the camera maintained the same distance $(50 \mathrm{~cm})$. No adjustments of pixels, colour, brightness and contrast were applied to the images. The photographs produced were parts of larger images that were selected without obscuring, eliminating or misrepresenting any information that was present in the originals.

\section{3 | RESULTS AND DISCUSSION}

Different-sized P(St-MMA-AA) composite latex nanospheres were successfully synthetised with soap-free emulsion polymerisation by changing both the temperature and stirring speed of the reactional mixture. DLS was used to measure the size distribution profile of nanospheres (data not shown). The zeta potential of the nanospheres ranged from $-45 \pm 0.5$ to $-64 \pm 0.2$, indicating good stability of the colloidal suspension. The calculated PDI of P(St-MMA-AA) nanospheres was determined as 0.1 , confirming their high monodispersity, uniformity and propensity for generating highly ordered structures. However, since DLS has previously been associated with errors, the observed average diameters and respective associated standard deviations were calculated by STEM (Table 1). STEM analyses (Figure 1) at high magnification $(200000 \times)$ confirmed that the $\mathrm{P}(\mathrm{St}-$ MMA-AA) latex spheres were composed of shell rich in poly(acrylic acid) (PAA) and poly(methyl methacrylate) (PMMA) covering the polystyrene (PSt) domains in the core, as previously reported. ${ }^{6}$ This can be observed in Figure 1A, where the PSt can be easily identified as the darker core surrounded by a lighter shell of PAA and PMMA. The STEM images also confirm the highly monodisperse PC suspensions, and the reproducibility of the synthesis method in obtaining specific nanosphere sizes with only a few minor

TA B LE 1 Different reaction conditions tested in poly(styrenemethyl methacrylate-acrylic acid) synthesis

\begin{tabular}{|lll}
\hline Temperature, ${ }^{\circ} \mathbf{C}$ & Stirring, rad/s & Size, $\mathbf{n m}$ \\
\hline 90 & 31.4 & $170 \pm 3.9$ \\
\hline 80 & 31.4 & $190 \pm 4.5$ \\
\hline 70 & 31.4 & $210 \pm 2.8$ \\
\hline 65 & 31.4 & $230 \pm 3.4$ \\
\hline 60 & 31.4 & $250 \pm 5.1$ \\
\hline 80 & 41.9 & $190 \pm 4.5$ \\
\hline 80 & 20.9 & $170 \pm 4.9$ \\
\hline
\end{tabular}



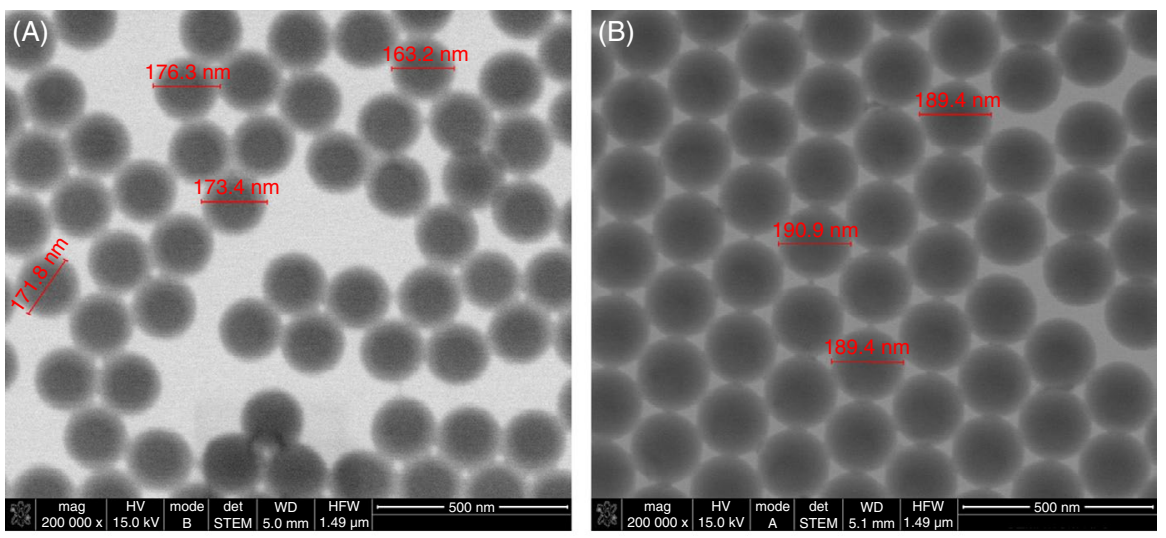

F I G U RE 1 Scanning transmission electron microscopy images of $c a .170$, 190, 210 and $250 \mathrm{~nm}$ poly(styrene-methyl methacrylate-acrylic acid) nanospheres
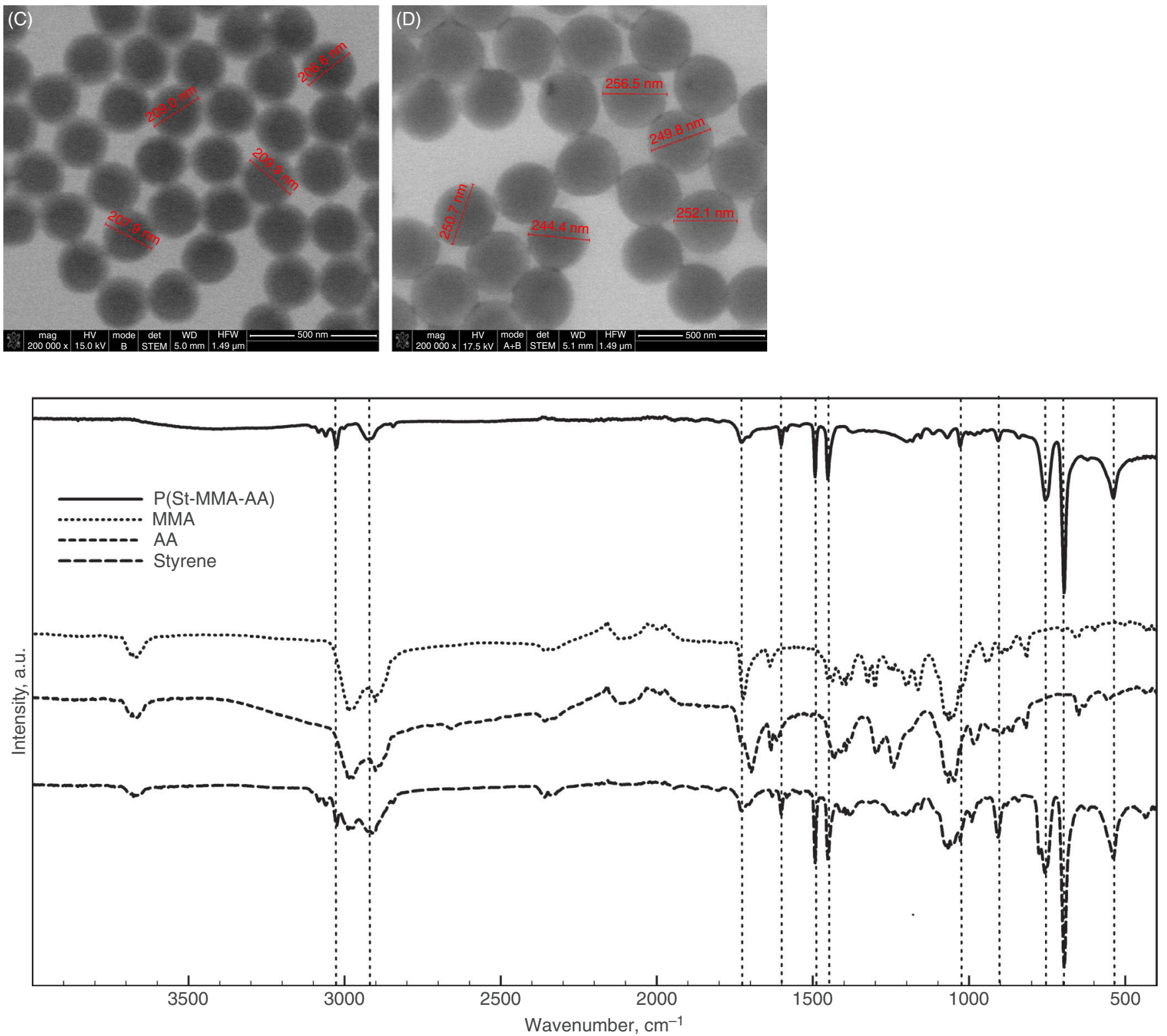

F I G U R E 2 Attenuated total reflection-Fourier Transform-infrared spectra from styrene, methyl methacrylate (MMA), acrylic acid (AA) and poly(styrene-methyl methacrylate-acrylic acid) (P(St-MMA-AA))

differences in diameter. ATR-FTIR spectra of the nanospheres (Figure 2) were consistent with previous reports, which confirmed that the structure of the P(St-MMA-AA) nanosphere consisted of a PSt core covered in PAA and PMMA. ${ }^{6}$ The FTIR spectra of the synthetised nanospheres represent not only the sum of the single reagents, but also 

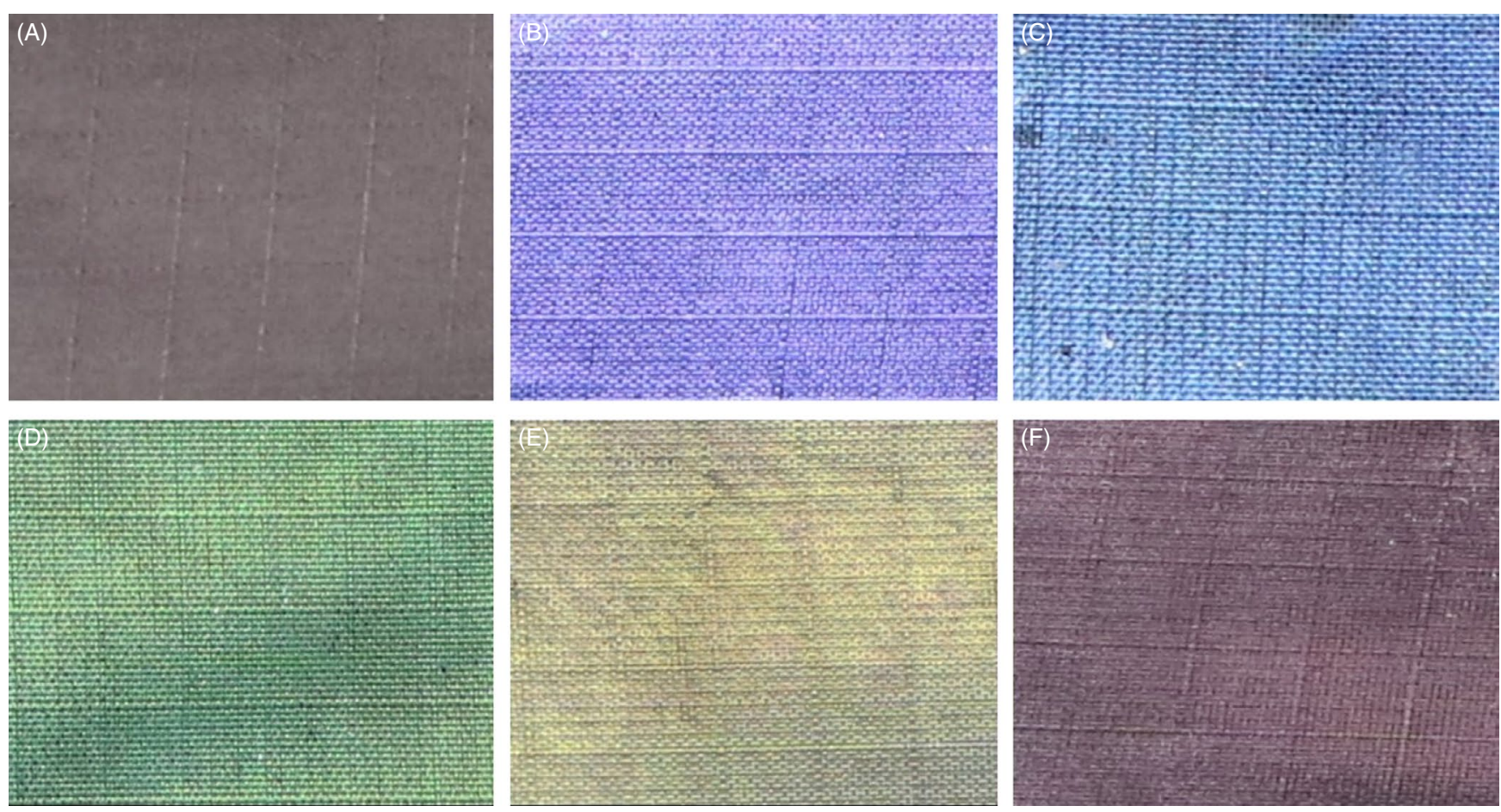

F I G U RE 3 Photographs of (A) uncoated polyamide (PA) fabric and PA fabric coated with different-sized poly(styrene-methyl methacrylateacrylic acid) nanospheres of $c a$. (B) 170, (C) 190, (D) 210, (E) 230 and (F) $250 \mathrm{~nm}$ produced by the dip-drawing method

TA B L E 2 Colour coordinates, black-white ( $L^{*}$, lightness), red-green $\left(a^{*}\right)$ and yellow-blue $\left(b^{*}\right)$, for uncoated polyamide (PA) fabric and PA fabrics coated with different-sized poly(styrene-methyl methacrylate-acrylic acid) nanospheres

\begin{tabular}{|lrrr} 
& \multicolumn{3}{c}{ CIELab colour coordinates } \\
\cline { 2 - 4 } PA fabric & \multicolumn{1}{c}{$\boldsymbol{L}^{*}$} & \multicolumn{1}{c}{$\boldsymbol{a}^{*}$} & \multicolumn{1}{c}{$\boldsymbol{b}^{*}$} \\
\hline Uncoated & 21.1 & 0.5 & -1.1 \\
\hline ca. 170 nanospheres & 34.6 & 13.2 & -30.8 \\
\hline ca. 190 nanospheres & 38.5 & 2.6 & -28.0 \\
\hline ca. 210 nanospheres & 49.8 & -27.0 & 11.5 \\
\hline ca. 230 nanospheres & 56.0 & -5.6 & 12.7 \\
\hline ca. 250 nanospheres & 33.5 & 5.8 & -3.0 \\
\hline
\end{tabular}

provide proof of the reactions occurring among the constituent materials, as indicated by the significant reductions in those peaks associated with either alcoholic or ether $\mathrm{C}-\mathrm{O}$ stretching at $1050-1100 \mathrm{~cm}^{-1}$, as well as the disappearance of the $\mathrm{C}-\mathrm{O}$ peak associated with the acid groups of AA at $1200-1300 \mathrm{~cm}^{-1}$. The small peak at $1728 \mathrm{~cm}^{-1}$ indicates the presence of carboxyl groups on the surface of the P(StMMA-AA) nanospheres. The peak at $1601 \mathrm{~cm}^{-1}$ is associated with the $\mathrm{C}=\mathrm{C}$ stretching vibrations of the benzene ring of the styrene, while the peaks at 1493 and $1452 \mathrm{~cm}^{-1}$ are related to the $\mathrm{CH}_{2}$ scissoring and $\mathrm{CH}_{3}$ asymmetric stretching or deformation of the $\mathrm{C}-\mathrm{H}$ bonds in the methyl groups. The peaks at 1028 and $756 \mathrm{~cm}^{-1}$ were assigned to the $\mathrm{C}-\mathrm{O}-\mathrm{C}$ symmetric stretching vibrations and $\mathrm{CH}_{2}$ rocking in-plane bending of the MMA, respectively. ${ }^{12}$

For the nanosphere synthesis, the reaction time was maintained at the previously optimised period of 5 hours. Further increases of time did not significantly improve monomer conversion, and can cause heterogeneous nucleation if the monomer feed rate is substantially lower than the polymerisation rate. ${ }^{30} \mathrm{P}(\mathrm{St}-\mathrm{MMA}-\mathrm{AA})$ synthesis at $80^{\circ} \mathrm{C}$ and $300 \mathrm{rpm}$ ( $c a .190 \mathrm{~nm}$ ) was used as a control parameter reaction to evaluate the differences obtained when the temperature and stirring speed were altered. Thus, at higher temperatures $\left(\mathrm{eg}, 90^{\circ} \mathrm{C}\right)$, smaller PC nanospheres were obtained with a size of $c a .170 \mathrm{~nm}$. As the temperature was lowered, larger-sized nanoparticles were obtained, of $c a$. $210 \mathrm{~nm}$ at $70^{\circ} \mathrm{C}, c a .230 \mathrm{~nm}$ at $65^{\circ} \mathrm{C}$ and $c a .250 \mathrm{~nm}$ at $60^{\circ} \mathrm{C}$. Raising the stirring speed to $400 \mathrm{rpm}$ did not significantly alter the particle sizes. On the other hand, when the stirring speed was lowered to $200 \mathrm{rpm}$, smaller nanoparticles were obtained (ca. $170 \mathrm{~nm}$ ). As expected, decreasing the reaction temperature from 90 to $60^{\circ} \mathrm{C}$ significantly decreased the conversion of the monomers at the end of the polymerisation, leading to an increase in PC size and a slight narrowing of the nanosphere size distribution. ${ }^{31}$ Higher reaction temperatures (data not shown) led to degradation and polydisperse nanosphere distribution, due to the instability of the monomer bulk phase polymerisation. Also, the stirring rate can have an important impact upon PC size; however, this is more difficult to control because it produces a 

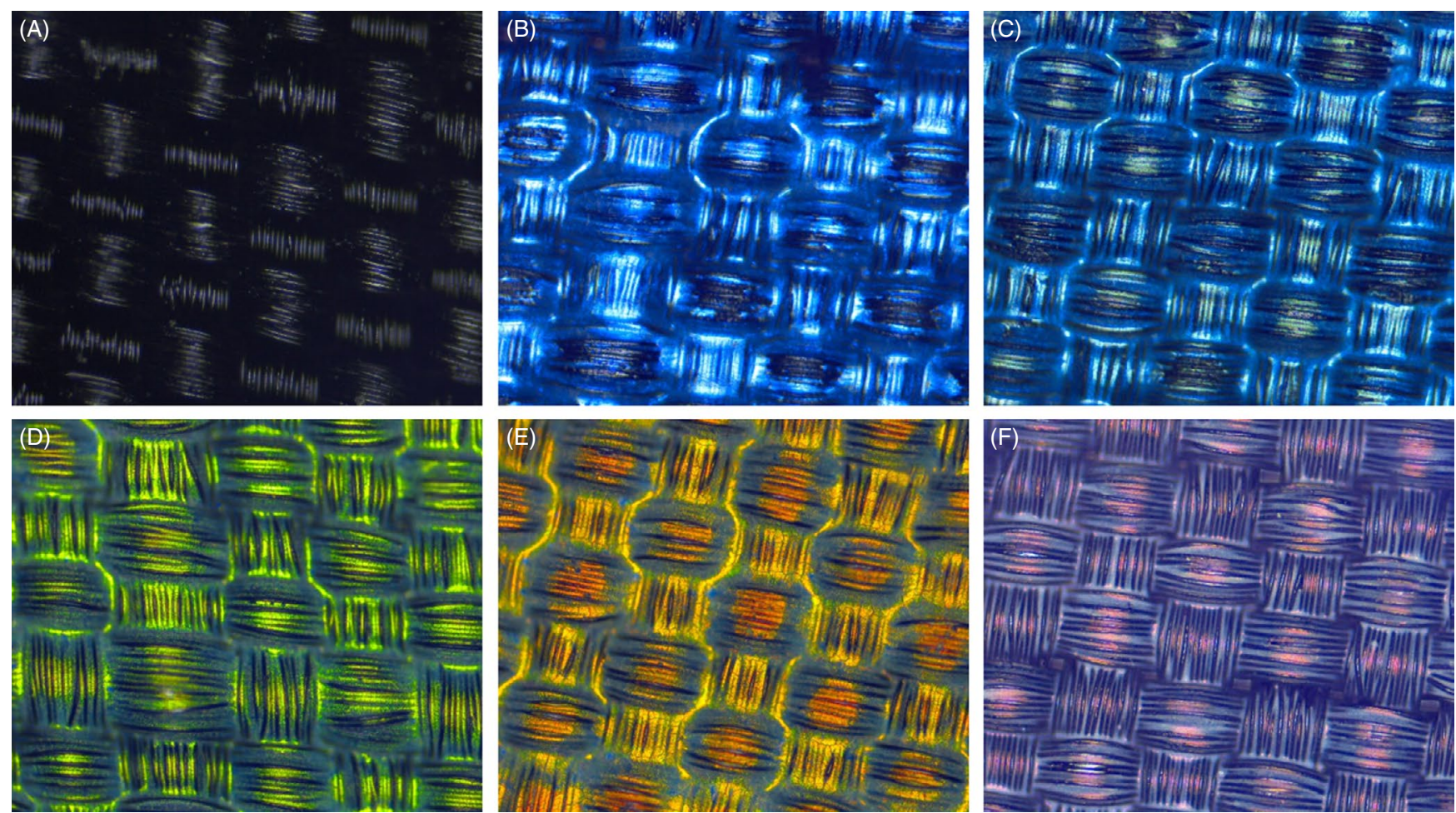

F I G U R E 4 Optical microscopy images (100× magnification) of (A) uncoated polyamide (PA) fabric and PA fabric coated with poly(styrenemethyl methacrylate-acrylic acid) nanospheres of $c a$. (B) 170, (C) 190, (D) 210, (E) 230 and (F) $250 \mathrm{~nm}$

complex chaotic environment that is also a function of the temperature being used. Nevertheless, it was possible to observe that an increase from 300 to $400 \mathrm{rpm}$ at a high reaction temperature did not have a significant impact upon PC size. On the other hand, nanosphere size decreased at $200 \mathrm{rpm}$. This effect can be attributed to the low amount of surfactant used in the reaction mixture. Under these conditions, due to the higher stability provided by the lower stirring velocity, the monomer did not polymerise on the surface of the seed latex nanosphere, but rather instead in the monomer droplets produced by stirring. However, due to the absence of the stabilising properties of the surfactant, the PCs formed are not able to reach a high degree of polymerisation while maintaining a low size. ${ }^{32}$
Gravitational sedimentation as a deposition method was quickly rejected after a few attempts because it was not possible to produce acceptable structural colour or iridescence. Dip-drawing was the preferred deposition method, and it was performed directly in the reaction mixture $(15 \% \mathrm{v} / \mathrm{v})$, saving both time and energy by rapidly obtaining good structural coloration and iridescence (Figure 3). Colour coordinates $\left(L^{*}, a^{*}\right.$ and $b^{*}$ ) were determined (Table 2) in order to confirm the structural colour formation. $L^{*}$ represents the lightness of the fabric and can vary from 0 (black object) to 100 (white reflector), $a^{*}$ designates green for negative and red for positive values, and $b^{*}$ indicates blue for negative and yellow for positive values. Compared with the uncoated substrate, coated PA fabrics displayed a general increase in $L^{*}$, indicating an
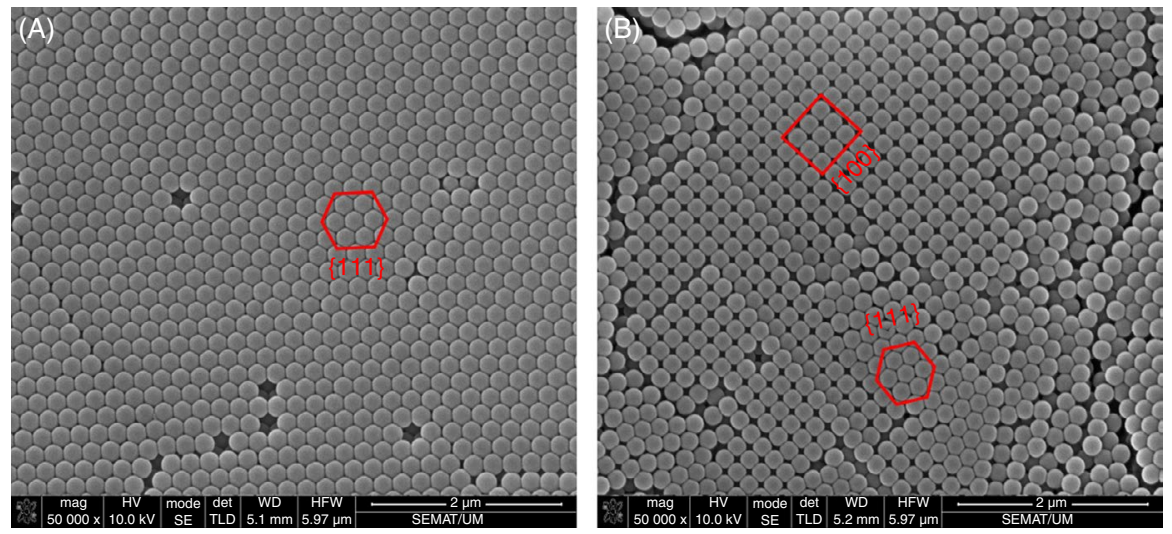

FIGURE 5 Scanning electron micrographs of polyamide (PA) fabric coated with $190 \mathrm{~nm}$ nanospheres, showing (A) a hexagonal closely packed structure, and (B) in the [100] plane, a square arrangement in the out-of-plane surfaces 
T A B LE 3 Specular gloss unit (GU) measurements for uncoated polyamide (PA) fabric and PA fabrics coated with different-sized nanospheres at $20^{\circ}, 60^{\circ}$ and $85^{\circ}$

\begin{tabular}{|llll|}
\hline PA fabric & $\mathbf{2 0}^{\circ}$ & $\mathbf{6 0}^{\circ}$ & $\mathbf{8 5}^{\circ}$ \\
\hline Uncoated & 0.1 & 0.4 & 1.1 \\
\hline ca. 170 nanospheres & 0.2 & 1.9 & 4.5 \\
\hline ca. 190 nanospheres & 0.3 & 1.6 & 3.8 \\
\hline ca. 210 nanospheres & 0.4 & 1.6 & 2.9 \\
\hline ca. 230 nanospheres & 0.6 & 2.7 & 4.5 \\
\hline ca. 250 nanospheres & 0.1 & 0.9 & 2.0 \\
\hline
\end{tabular}

increase in the lightness of the fabrics. At $170 \mathrm{~nm}$, coated fabric displayed a greater reddish and blue colour (positive $a^{*}$ and negative $b^{*}$ ) than uncoated fabric. The other coatings showed lower $b^{*}$ (ie, were bluer) at $190 \mathrm{~nm}$, much lower $a^{*}$ (ie, were greener) at $210 \mathrm{~nm}$, and a greener and yellower coating at $230 \mathrm{~nm}$ and a redder coating at $250 \mathrm{~nm}$. These results accord with Bragg's law, which states that changes in particle size will produce different colours, and that larger nanoparticles will reflect higher wavelengths with a red shift as their size increases. It is well known that PCs can diffract light as a function of their periodic distribution, resulting in wavelengths that can be predicted by Bragg's equation $(\lambda=2 d n)$, and therefore the resulting wavelengths and thus the colour can be tuned by either modifying the distance between latex spheres $(d)$ or the effective refractive index of the coating (n). ${ }^{33}$ Consequently, the changes in colour should indicate the positions of the stopbands of the corresponding PC coatings as a function of the arrangement of the nanospheres on the fabric's surface. In order to confirm this assumption, the deposition of PCs upon the PA fabric surface was analysed by optical microscopy (Figure 4) and SEM (Figure 5). SEM analysis confirmed the deposition of PCs upon the PA fabric surface as a well-organised closely packed array, which can be classified as a hexagonal closely packed distribution. In this configuration, the PCs are in a FCC arrangement in a closely packed plane [111] that is orientated parallel to the substrate, with each nanoparticle surrounded by six others in the same plane (Figure 5A). ${ }^{34}$ However, in the [100] plane a square arrangement was observed in the sloping out-ofplane surfaces near to the fibre's cross-intersections (Figure $5 \mathrm{~B})$. To enhance the chroma of the structural colour, a blackdyed fabric is required as a background to efficiently absorb the transmitted and scattered light outside the bandgap of PCs. ${ }^{26}$ The specular gloss of PA fabrics coated with different-sized nanospheres were recorded as higher than that of an uncoated PA fabric (Table 3). Specular gloss is largely a function of the refractive index of the surface and the angle of incidence of light. The greater the amount of reflected light, the glossier the surface. In general, to be considered a high gloss surface, a material must possess at least 70 gloss units (GU) at an angle of incidence of $60^{\circ}{ }^{35}$ It is clear from the results obtained that the surfaces did not possess any specular gloss properties. There was a slight increase in gloss at $85^{\circ}$ in the bright colours, but nothing significant was observed, confirming that the PC-coated surfaces reflect light mostly by diffuse reflection. ${ }^{36}$ The iridescent effect, a characteristic
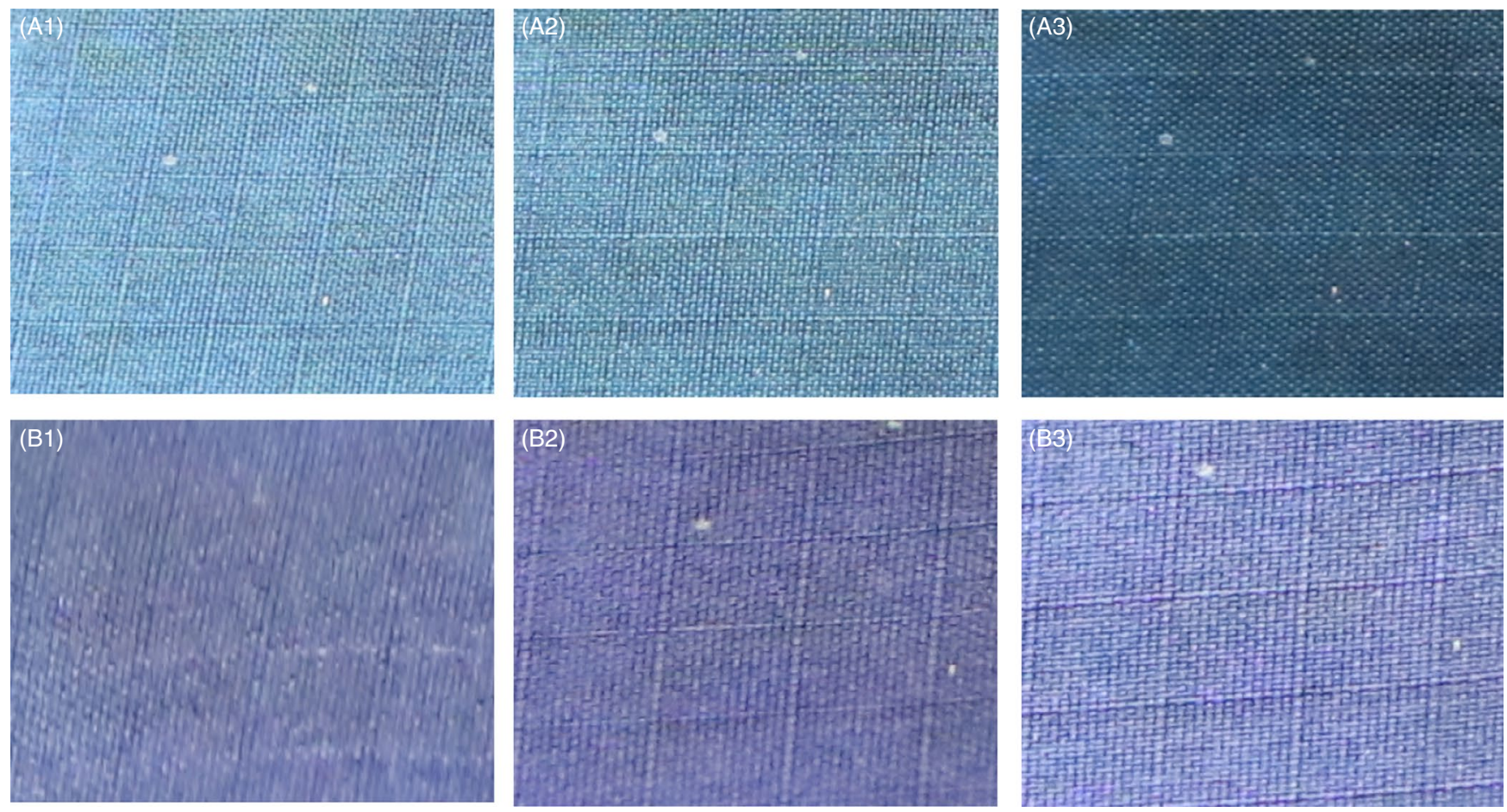

F I G U RE 6 Polyamide (PA) 6,6 fabrics with $c a .190 \mathrm{~nm}$ nanospheres at different observation angles: row (A) $45^{\circ}$ and row (B) $90^{\circ}$, with different light incidence angles, (A1, B1) $70^{\circ},(\mathrm{A} 2, \mathrm{~B} 2) 45^{\circ}$ and (A3, B3) $30^{\circ}$ 
which is typical of PCs, was confirmed. When the angle of observation of a sample was changed, the colour observed also changed (Figure 6). At an observation angle of $45^{\circ}$, the colour changed from a light to a dark blue as the incident light angle decreased, and at an observation angle of $90^{\circ}$, it changed from a dark to a light violet. The colour difference between the two angles of observation demonstrated the iridescence effect of the deposited nanospheres upon PA fabric. The colour and opalescence produced are the result of both Bragg's diffraction of the well-ordered PC coatings, and Mie scattering of the disordered crystal structures due to the uneven surface of the fabric that promotes some random orientation and cracks, especially near to the intersection of the yarns. $^{24}$

\section{\begin{tabular}{l|l}
4 & CONCLUSIONS
\end{tabular}}

Monodisperse and stable composite latex nanospheres of P(St-MMA-AA) were successfully synthetised at different sizes, as confirmed by STEM and FTIR analysis. At high temperatures, small-sized PC nanoparticles were obtained, while at low temperatures the nanoparticle size increased. Lowering the stirring speed also increased the size of P(StMMA-AA) nanoparticles. A higher stirring speed did not have any significant influence upon nanosphere size compared with the control reaction. PCs applied to black PA 6,6 fabrics by the dip-drawing method displayed different colours according to each PC's size, namely, violet ( $c a .170 \mathrm{~nm}$ ), blue (ca. $190 \mathrm{~nm})$, green $(c a .210 \mathrm{~nm})$, yellow (ca. $230 \mathrm{~nm})$ and red (ca. $250 \mathrm{~nm}$ ). SEM analysis confirmed that the self-assembled structures were mainly based on a hexagonal closely packed arrangement with some square arrangements in the out-of-plane areas. Textile structural coloration produced this way may have the potential to significantly reduce pollution in textile dyeing processes by reducing the water and chemical consumption. In future research, it will be necessary to improve washing and friction fastness and to extend the depositions into other substrates such as cotton, silk and wool.

\section{ACKNOWLEDGEMENTS}

This work was funded by European Regional Development funds (FEDER) through the Competitiveness and Internationalization Operational Program (POCI) COMPETE and by National Funds through Fundação para a Ciência e Tecnologia (FCT) - under the project POCI01-0145-FEDER-007136 and UID/CTM/00264/2019. Rui Fernandes (SFRH/BD/145269/2019) acknowledges FCT, Portugal, for its doctoral grant financial support. A. Zille also acknowledges financial support of the FCT through an Investigator FCT Research contract (IF/00071/2015) and the project PTDC/CTM-TEX/28295/2017 financed by FCT, FEDER and POCI in the frame of the Portugal 2020 program.

\section{ORCID}

Rui D. V. Fernandes (iD https://orcid.

org/0000-0001-9768-0628

Pedro Gomes iD https://orcid.org/0000-0002-1096-9590

Andrea Zille (iD https://orcid.org/0000-0001-5299-4164

António P. Souto (D) https://orcid.org/0000-0001-6439-4780

\section{REFERENCES}

1. Liu Z, Zhang Q, Wang H, Li Y. Structural colored fiber fabricated by a facile colloid selfassembly method in micro-space. Chem Commun. 2011;47:12801-12803.

2. Li M, Song Y. Polymer photonic crystals. In: Mark FH, ed. Encyclopedia of polymer science and technology. Hoboken: John Wiley \& Sons, Inc.; 2014:1-46.

3. Wang H, Zhang KQ. Photonic crystal structures with tunable structure color as colorimetric sensors. Sensors. 2013;13:4192-4213.

4. Zhao Y, Xie Z, Gu H, Zhu C, Gu Z. Bio-inspired variable structural color materials. Chem Soc Rev. 2012;41:3297-3317.

5. Vignolini S, Glover BJ, Rowland AV, et al. Pointillist structural color in Pollia fruit. PNAS. 2012;109:15712-15715.

6. Yavuz G, Felgueiras HP, Ribeiro AI, Seventekin N, Zille A, Souto AP. Dyed poly(styrene-methyl methacrylate-acrylic acid) photonic nanocrystals for enhanced structural color. ACS Appl Mater Interfaces. 2018;10:23285-23294.

7. Zhou L, Li Y, Liu G, Fan Q, Shao J. Study on the correlations between the structural colors of photonic crystals and the base colors of textile fabric substrates. Dyes Pigm. 2016;133:435-444.

8. Gao W, Rigout M, Owens H. The structural coloration of textile materials using self-assembled silica nanoparticles. J Nanopart Res. 2017;19:1-11.

9. Fudouzi H, Sawada T. Photonic rubber sheets with tunable color by elastic deformation. Langmuir. 2006;22:1365-1368.

10. Nucara L, Greco F, Mattoli V. Electrically responsive photonic crystals: a review. J Mater Chem C. 2015;3:8449-8467.

11. Rong JH, Ji LJ, Yang ZZ. Some key ordered macroporous composites. Chinese J Polym Sci. 2013;31:1204-1217.

12. Ikhuoria EU, Omorogbe SO, Sone BT, Nuru ZY, Khamlich S, Maaza M. Raspberry-like and other hexagonal close-packed morphologies of P(St-MMA-AA) particles obtained from different emulsifiers for photonic applications. J Mod Opt. 2018;65:1817-1826.

13. Tan P-F, Wang C-F, Wang X-Q, Ji W-Q, Chen M, Chen S. Highly crystallized brilliant polymeric photonic crystals via repulsion-induced precipitation assembly toward multiresponsive colorimetric films. Macromol Mater Eng. 2016;301:1363-1373.

14. Ding T, Smoukov SK, Baumberg JJ. Stamping colloidal photonic crystals: A facile way towards complex pixel colour patterns for sensing and displays. Nanoscale. 2015;7:1857-1863.

15. Song Y, Wang J, Huang Y, et al. Inkjet printed colloidal photonic crystal microdot with fast response induced by hydrophobic transition of poly(N-isopropyl acrylamide). J Mater Chem. 2012;22:21405-21411.

16. Hölscher H, Lemmer U, Faisal A, Hünig R, Siddique RH. Fabrication of hierarchical photonic nanostructures inspired by Morpho butterflies utilizing laser interference lithography. Opt Mater Express. 2015;5:996-1005.

17. Xu L, Wang J, Song Y. Electrically tunable polypyrrole inverse opals with switchable stopband, conductivity, and wettability. Chem Mater. 2008;20:3554-3556. 
18. Stein A, Wilson BE, Rudisill SG. Design and functionality of colloidal-crystal-templated materials - chemical applications of inverse opals. Chem Soc Rev. 2013;42:2763-2803.

19. Liu G, Zhou L, Zhang G, et al. Fabrication of patterned photonic crystals with brilliant structural colors on fabric substrates using ink-jet printing technology. Mater Des. 2017;114:10-17.

20. Liu G, Zhou L, Fan Q, Chai L, Shao J. The vertical deposition self-assembly process and the formation mechanism of poly(styrene-co-methacrylic acid) photonic crystals on polyester fabrics. $J$ Mater Sci. 2016;51:2859-2868.

21. Liu G, Shao J, Zhang Y, et al. Self-assembly behavior of polystyrene/methacrylic acid (P(St-MAA)) colloidal microspheres on polyester fabrics by gravitational sedimentation. J Text Inst. 2015;106:1293-1305.

22. Zhou L, Wu Y, Liu G, Shao J, Fan Q, Wang C. Optical properties of three-dimensional P(St-MAA) photonic crystals on polyester fabrics. Opt Mater. 2015;42:72-79.

23. Zeng Q, Ding C, Li Q, et al. Rapid fabrication of robust, washable, self-healing superhydrophobic fabrics with noniridescent structural color by facile spray coating. RSC Adv. 2017;7:8443-8452.

24. Gao W, Rigout M, Owens H. Optical properties of cotton and nylon fabrics coated with silica photonic crystals. Opt Mater Express. 2017;7:341-353.

25. Yuan W, Zhou N, Shi L, Zhang K-Q. Structural coloration of colloidal fiber by photonic band gap and resonant Mie scattering. ACS Appl Mater Interfaces. 2015;7:14064-14071.

26. Shi X, He J, Xie X, Dou R, Lu X. Photonic crystals with vivid structure color and robust mechanical strength. Dyes Pigm. 2019;165:137-143

27. Yavuz G, Zille A, Seventekin N, Souto AP. Structural coloration of chitosan-cationized cotton fabric using photonic crystals. IOP Conf Ser Mater Sci Eng. 2017;254:1-6.

28. Yavuz G, Zille A, Seventekin N, Souto AP. Structural coloration of chitosan coated cellulose fabrics by electrostatic self-assembled poly (styrene-methyl methacrylate-acrylic acid) photonic crystals. Carbohydr Polym. 2018;193:343-352.
29. Wang J, Wen Y, Ge H, et al. Simple fabrication of full color colloidal crystal films with tough mechanical strength. Macromol Chem Phys. 2006;207:596-604.

30. Kang K, Kan C, Du Y, Yeung A, Liu D. Morphology control of soap-free seeded P(St-EA-AA) latex particles. Eur Polym J. 2005;41:1510-1518.

31. Zhang S, Chen J, Taha M. Synthesis of monodisperse styrene/methyl methacrylate/acrylic acid latex using surfactant-free emulsion copolymerization in air. J Appl Polym Sci. 2009;114:1598-1605.

32. Kong XZ, Ruckenstein E. Core-shell latex particles consisting of polysiloxane-poly(styrene-methyl methacrylate-acrylic acid): Preparation and pore generation. J Appl Polym Sci. 1999;73:2235-2245.

33. Tian E, Wang J, Zheng Y, Song Y, Jiang L, Zhu D. Colorful humidity sensitive photonic crystal hydrogel. J Mater Chem. 2008;18:1116-1122.

34. Zhang Y-Q, Wang J-X, Ji Z-Y, et al. Solid-state fluorescence enhancement of organic dyes by photonic crystals. J Mater Chem. 2007; 17:90-94.

35. Lee J-W, Son S-M, Hong S-I. Characterization of protein-coated polypropylene films as a novel composite structure for active food packaging application. J Food Eng. 2008;86:484-493.

36. Ajeli S, Ahmadvand Z. Investigation of the two-bar warp-knitted fabric structure effect on luster value. J Eng Fibers Fabr. 2018;9:32-37.

How to cite this article: Fernandes RDV, Gomes P, Zille A, Souto AP. The influence of chemical reaction conditions upon poly(styrene-methyl methacrylateacrylic acid) synthesis: Variations in nanoparticle size, colour and deposition methods. Coloration Technol. 2019;00:1-9. https://doi.org/10.1111/cote.12452 